\title{
CITRIC ACID AS MULTIFUNCTIONAL AGENT IN BLOWING FILMS OF STARCH/PBAT
}

Patrícia Salomão Garcia, Maria Victória Eiras Grossmann* e Fábio Yamashita

Departamento de Ciência e Tecnologia de Alimentos, Universidade Estadual de Londrina, CP 6011, 86051-970 Londrina - PR, Brasil Suzana Mali

Departamento de Bioquímica, Universidade Estadual de Londrina, CP 6011, 86051-970 Londrina - PR, Brasil

Luiz Henrique Dall'Antonia e Wagner José Barreto

Departamento de Química, Universidade Estadual de Londrina, CP 6011, 86051-970 Londrina - PR, Brasil

Recebido em 20/10/10; aceito em 14/4/11; publicado na web em 10/6/11

\begin{abstract}
Citric acid was used as a compatibilizer in the production of starch and PBAT films plasticized with glycerol and processed by blow extrusion. Films produced were characterized by WVP, mechanical properties, FT-IR-ATR and SEM. WPV ranged from 3.71 to $12.73 \times 10^{-11} \mathrm{~g} \mathrm{~m}^{-1} \mathrm{~s}^{-1} \mathrm{~Pa}^{-1}$, while tensile strength and elongation at break ranged from 1.81 to $7.15 \mathrm{MPa}$ and from 8.61 to $23.63 \%$, respectively. Increasing the citric acid concentration improved WVP and slightly decreased film resistance and elongation. The films micrographs revealed a more homogeneous material with the addition of citric acid. However, the infrared spectra revealed little about cross-linking esterification reaction.
\end{abstract}

Keywords: starch; polyester; compatibilization.

\section{INTRODUCTION}

To overcome the fragility of films made only from starch and improve their elasticity and handling, plasticizers are added to the polymer matrix, which form thermoplastic starch (TPS) under high temperature and shearing conditions. Plasticizers directly interfere in the intra- and intermolecular hydrogen bonds, lending to films with greater flexibility. Nevertheless, the hydrophilic character of the most commonly used plasticizers (polyols) makes films susceptible to atmospheric conditions..$^{1-3}$ To curb this problem, several authors have proposed the development of blends of natural polymers with biodegradable synthetic polymers that presented good properties and processability similar to that of conventional plastics. ${ }^{3-5}$ Poli(butileneadipate-co-tereftalate) (PBAT) is an aliphatic-aromatic co-poliester that is degraded in few weaks by enzymes naturally presents in the ambient. ${ }^{5,6}$ Nevertheless, its high cost and, in several cases, low compatibility with starch at molecular level are limiting factors for its use. Strategies have been developed to improve the compatibility between starch and polyesters. These strategies involve the addition of a compatibilizer to modify at least one polymer initially present in the blend. A compatibilizer is a compound that stays in the interface of the two phases, reducing the interface energy and affording better adhesion..$^{4,7}$ The most commonly used compatibilizers are maleic anhydride and citric acid. ${ }^{3,48-10}$ Compatibilizers often have two or more reactive groups in their structure that can interact with other functional groups present in the polymer chains. Citric acid has a multicarboxilic structure, which justifies its use as a compatibilizer. This structure is responsible for its different functions: plasticizer (when in excess); crosslinking agent, ${ }^{3,4}$ and hydrolytic agent. ${ }^{3}$ Reactive extrusion is a process recommended for compatibilization strategy, as functional groups can be grafted in polymeric chains in a rapid and continual way, justifying commonly considering extruders as chemical reactors. ${ }^{11}$

*e-mail: victoria@uel.br
The objective of this work was to determine the effect of components starch/PBAT/glycerol and citric acid on the microstructural, mechanical, and barrier properties of blown films.

\section{EXPERIMENTAL}

\section{Material}

Films were manufactured with cassava starch (Indemil - Paranavaí - Brazil), glycerol (Synth - Brazil), and citric acid (Dinamica - Brazil). The biodegradable polyester used was poly(butylene-adipate-co-terephthalate) produced by BASF under trade name Ecoflex ${ }^{\circledR}$ S BX 7025.

\section{Methods}

Film production

Films containing starch, PBAT, glycerol, with and without citric acid were manufactured using a laboratory mono-screw extruder (model EL-25, BGM, São Paulo, Brazil) with screw diameter D = 25 $\mathrm{mm}$ and screw length $28 \mathrm{D}$. Firstly, citric acid was dissolved in glycerol and then manually mixed with PBAT and starch. The films were produced in two stages. In the first stage, for the pellets production, the mixtures were extruded with a temperature of 120/120/120/130 ${ }^{\circ} \mathrm{C}$ and screw speed of $40 \mathrm{rpm}$. Then, the pellets were extruded again to obtain the film with a temperature profile of 120/120/120/130/130 ${ }^{\circ} \mathrm{C}$, with the same screw speed. These conditions were defined in preliminary tests.

\section{Characterization}

\section{Water vapor permeability (WVP)}

The tests were conducted using ASTM method E-96-00 (2000) ${ }^{12}$ with some modifications. The film were conditioned at $53 \% \mathrm{RH}$ at $25^{\circ} \mathrm{C}$ for $48 \mathrm{~h}$, and the each film sample was fixed in a circular opening of a permeation cell with $60 \mathrm{~mm}^{2}$ of diameter with silicone grease. 
The interior of the cell was filled with anhydrous calcium chloride $(0 \% \mathrm{RH})$ and was stored at $25^{\circ} \mathrm{C}$ in a desiccator containing sodium chloride saturated solution was to provide $75 \% \mathrm{RH}$. Weighing was preformed nine successive times every $2 \mathrm{~h}$. Changes in the weight of the cell or mass gain $(m)$ were plotted as a function of time $(t)$. The slope of each line was calculated by linear regression and the water vapor permeation ratio (WVPR) was obtained with Equation 1:

$$
\text { WVPR }=(\mathrm{m} / \mathrm{t}) \cdot(1 / \mathrm{A})
$$

where $\mathrm{m} / \mathrm{t}$ is the angular coefficient of the curve and $A$ is the sample permeation area.

The WVP was calculated as:

$$
\mathrm{WVP}=\mathrm{WVTR} . \mathrm{t} / \mathrm{s} p\left(\mathrm{RH}_{1}-\mathrm{RH}_{2}\right)
$$

where $t$ is the mean sample thickness (m), $s p$ is the water vapor saturation pressure at the assay temperature $(\mathrm{Pa}), R H_{l}$ is the relative humidity of the desiccator and $\mathrm{RH}_{2}$ is the relative humidity in the interior of the permeation cell. The tests were conducted in triplicate.

\section{Mechanical properties}

Tensile properties were determined with a texture analyzer, Stable MicroSystems (model TATX2i, England), according to the ASTM (D882-00) method (2001). ${ }^{13}$ The samples were cut (100 x $\left.2.5 \mathrm{~mm}\right)$ and previously conditioned at $53 \%$ of $\mathrm{RH}\left(\mathrm{Mg}\left(\mathrm{NO}_{3}\right)_{2}\right.$ solution) and $25^{\circ} \mathrm{C}$ for $48 \mathrm{~h}$. The crosshead speed was set at $0.83 \mathrm{~mm} / \mathrm{s}$ (load cell $25 \mathrm{~kg}$ ) and the initial distance between the grips was $50 \mathrm{~mm}$. The parameters determined were: tensile strength (MPa) and elongation at break (\%). Measurements were performed in five replicates.

\section{Scanning electron microscopy (SEM)}

The fracture surfaces of starch/glycerol/PBAT blends with and without citric acid were assessed with a scanning electron microscope FEI Quanta 200, operated at an acceleration voltage of $20 \mathrm{kV}$. The samples were cooled in liquid nitrogen, and then broken. The fracture surfaces were vacuum coated with gold for SEM. Images were taken with 800,1600 and $4000 \mathrm{x}$ of magnification.

\section{Fourier transform infrared (FT-IR) spectroscopy}

The FT-IR spectrum of the glycerol and citric acid and their mixtures with and without heating were obtained with spectrophotometer FT-IR 8300 (Shimadzu). Heating $\left(130{ }^{\circ} \mathrm{C} / 3 \mathrm{~min}\right.$ ) was done to simulate the thermal conditions to which the mixture had been subjected in the extruder during film production. Analyses were conducted in the mid-infrared region with Fourier Transform covering the wavenumber from 4000 to $400 \mathrm{~cm}^{-1}$ with spectrum resolution of $4 \mathrm{~cm}^{-1}$. Two hundred scans were performed for each sample. The spectra of films were obtained by FT-IR-ATR (Attenuated Total Reflectance) with the aid of a Thermoscientific Nicolet iS10 spectrophotometer. The probe with germanium beam was placed directly in contact with the surface of the films, with and without citric acid. For each spectrum, a resolution of $4 \mathrm{~cm}^{-1}$ was used in 100 scans in the $4000-700 \mathrm{~cm}^{-1}$ region. The region of interest in this work was of $2200-1200 \mathrm{~cm}^{-1}$, where it is easier to observe the possible formation of links related to esterification reactions.

\section{Statistical design}

The films were manufactured with different mixtures, as defined by an experimental design for ternary mixtures with components: glycerol (G) (7.5-10.5\% w/w), citric acid (CA) (2.5-4.5\% w/w), and starch/PBAT (SP) $(85.0-90.0 \% \mathrm{w} / \mathrm{w})$. A test formulation containing $0.5 \%$ citric acid, $7.5 \%$ glycerol and $92 \%$ starch/PBAT was also produced in preliminary tests, when the lower and upper constrains of the ternary mixtures were established. The produced films were characterized by mechanical properties (tensile strength and elongation at break) and water vapor permeability (WVP).

The statistical technique of desirability was used for simultaneous optimization of the evaluated properties specifying minimum WVP, maximum elongation at break, and intermediate resistance as desirable levels. This latter was established because it was impossible to select a mixture that presented low WVP, high elongation, and high resistance simultaneously. New films were produced: one with the selected optimal mixture (10.5\% glycerol, 3\% citric acid, $86.5 \%$ starch/PABT (w/w)) and another with a control mixture, without citric acid, maintaining approximately the same proportions between glycerol and starch/PBAT. In order to obtain the experimental design, perform data analysis, and plot response surface graphs, software Statistica (StatSoft, Inc. Tulsa, OK USA) ${ }^{14}$ version 7.0 was employed.

\section{RESULTS AND DISCUSSION}

\section{Morphology and properties of the blends}

The micrographs of the fracture of the film containing $0.5 \% \mathrm{CA}$ (Figure 1) show starch granules with altered conformation, similar in shape to donuts. This conformation is an evidence of crosslinking between citric acid and starch inside the granule, which may be partially responsible for the presence of rugosities observed by the naked eye on the surface of all films.

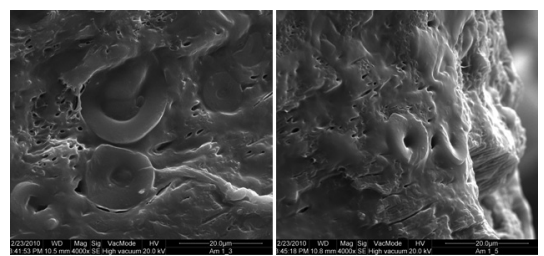

Figure 1. Micrographs of fracture starch/PBAT/glycerol blends compatibilized with citric acid (7.5\% glycerol, $0.5 \%$ citric acid, 92.0\% starch/PBAT) (film produced in preliminary tests.

According Xiaofei et al. ${ }^{15}$ and Wing, ${ }^{16}$ when CA is heated, it dehydrates to yield an anhydride, which might react with starch to form a starch-citrate derivative. Further heating would result in additional dehydration with cross-linking.

As the concentration of citric acid in the blends was increased from 0.5 to $2.5 \%$ (w/w), the amount of donuts in the material decreased (Figure 2). This suggests that the fragmentation of the starch granules is likely to have occurred during processing, due not only to the action of temperature and friction caused by extrusion, but also due to the specific action of citric acid, acting on the hydrolysis of the chains, as reported by Ning et al.. ${ }^{3}$

On the one hand, this fragmentation and molecular-size reduction may have improved the dissimination of the thermoplastic starch in the PBAT phase, creating structures that became more uniform as the concentration of citric acid increased (Figure 2). On the other hand, however, there could be a reduction in the strength of the material.

The effect of variables on mechanical properties of films (which thickness varied from 0,087 to $0,266 \mathrm{~mm}$ ) can be observed in Table 1 , which shows the mathematical models that best described the experimental results of tensile strength, elongation at break and water vapor permeability.

The interaction between glycerol and citric acid exerted greater influence on tensile strength, with a significant negative effect $(\mathrm{p}<$ 0.05). The same antagonist effect was observed for the interaction 

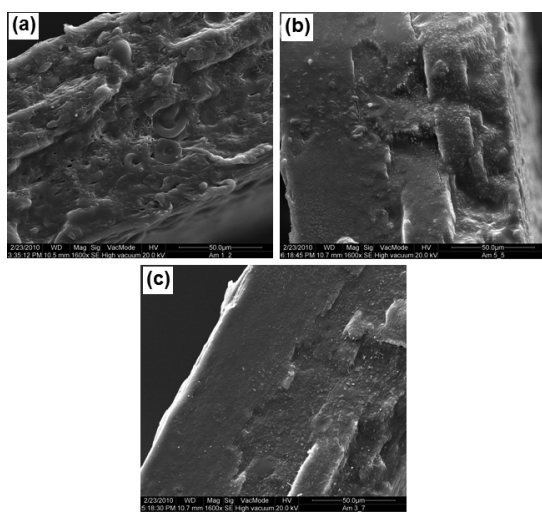

Figure 2. Micrographs of fracture starch/PBAT/glycerol blends compatibilized with citric acid at concentrations (w/w): (a) $0.5 \%$, (b) $1.5 \%$ and (c) $2.5 \%$ (films produced in preliminary tests)

Table 1. Mathematical model to tensile strength, elongation at break and WVP of films produced with starch/PBAT/glycerol/citric acid

\begin{tabular}{lr}
\hline Dependents variables & Model \\
\hline Tensile strength & $\mathrm{Y}=7,65 *(\mathrm{G})+19,01 *(\mathrm{CA})+7,10^{*}(\mathrm{SP})-$ \\
& $41,73 *(\mathrm{G})(\mathrm{CA})-5,03(\mathrm{G})(\mathrm{SP})-24,67 *(\mathrm{CA})(\mathrm{SP})$ \\
Elongation at break & $\mathrm{Y}=26,96 *(\mathrm{G})+17,35^{*}(\mathrm{CA})+9,85 *(\mathrm{SP})$ \\
& $\mathrm{Y}=29,03 *(\mathrm{G})+48,74 *(\mathrm{CA}) 9,89 *(\mathrm{SP})-$ \\
WVP & $127,05 *(\mathrm{G})(\mathrm{CA})-57,89 *(\mathrm{G})(\mathrm{SP})-83,57 *(\mathrm{CA})$ \\
& $(\mathrm{SP})+274,24 *(\mathrm{G})(\mathrm{CA})(\mathrm{SP})$ \\
\hline
\end{tabular}

*significant $(\mathrm{p}<0,05) ; \mathrm{Y}$ (dependents variables: tensile strength, elongation at break or WVP); (G): glycerol; (CA): citric acid; (SP): starch/PBAT.

between citric acid and starch/PBAT. Although all of the components had a significant positive effect $(\mathrm{p}<0.05)$, glycerol contributed the most to the increase in the elongation at break.

As can be seen in Figure 1S(a) (supplementary material), tensile strength of the films ranged from $<4$ to $<8$ (the experimental results ranged from 1.81 to $7.15 \mathrm{MPa}$ ). Tensile strenght slightly decreased when increase the concentration of citric acid at all polymer and glycerol rates. These results indicate that citric acid may have promoted not only crosslinking reactions, which accounts for reducing the film flexibility (Figure 1S(b), supplementary material), but also starch hydrolysis and/or plasticization. As previously observed by Shi et al., ${ }^{4}$ residual citric acid may also act as a plasticizer, reducing hydrogen linkages between starch chains and weakening the blend structure.

Elongation at break (Figure 1S(b), supplementary material) ranged from $<10$ to $<24$ (the experimental results ranged from 8.61 to $23.63 \%$ ), and, in the same manner, elongation also decreased with increasing citric acid concentration. The effect on elongation at break may be explained in considering that citric acid increased the interface adhesion between the two polymer chains (starch and PBAT), making a greater interaction between them possible. When the results of elongation and tensile strength of the films are analysed together, it is evident that the more important function that explains the effect of increasing levels of citric acid is the hydrolytic function.

Jiugao, Ning and Xiaofei ${ }^{9}$ also found that increasing the level (0.6 to $3.0 \%$ ) of citric acid added to thermoplastic corn starch decreased the elongation at break of the films (from 150 to $100 \%$ ) and the tensile strength (3.98 to $1.95 \mathrm{MPa}$ ).

The WVP was most affected by the interaction between components glycerol and citric acid (Table 1), which had a significant negative effect $(\mathrm{p}<0.05)$. The increase in the citric acid concentration, and consequently the reduction in the glycerol and/or starch/ PBAT concentrations, resulted in lower WVP values (Figure 1S(c), supplementary material), which experimental results ranged from 12.73 to $3.71 \times 10^{-11} \mathrm{~g} \mathrm{~m}^{-1} \mathrm{~s}^{-1} \mathrm{~Pa}^{-1}$. Beside introducing of ester groups in the starch chain which increases its hydrophobic character, this effect can be explained by the increase in the compatibilization among blends components promoted by citric acid, resulting in more homogeneous structures. The obtained WVP results were lower than those reported by Xiaofei et al. ${ }^{15}\left(2.04-2.63 \times 10^{-10} \mathrm{~g} \mathrm{~m}^{-1} \mathrm{~s}^{-1} \mathrm{~Pa}^{-1}\right)$ for starch films with $12 \%$ citric acid. Nevertheless, they did not use any biodegradable polyester, which may have contributed to reducing the hydrophilicity of the material, suggesting that the decrease in the WVP of the films obtained in this study may have been favored by the addition of PBAT.

According to the desirability technique the optimized formulation to achieve minimal WVP, maximal elongation, and intermediate resistance would require $3.0 \%$ citric acid, $10.5 \%$ glycerol, and $86.5 \%$ starch/PBAT (w/w). The film obtained with this formulation (Figure $3 \mathrm{~b}$ ), compared with the control film (without citric acid) (Figure 3a), showed a microstructural improvement, with a more compact and homogeneous structure. It also performed better during processing. Deformed donut-like starch granules were not observed, furthering the proposition about the hydrolytic effect of the increase in the citric acid concentration.

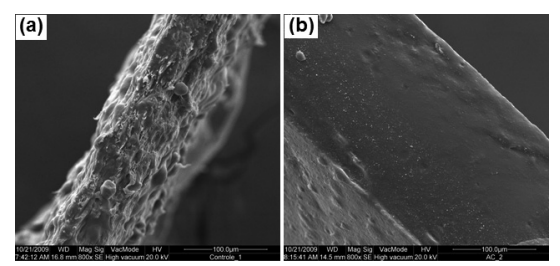

Figure 3. Micrographs of fractures of films: (a) starch/PBAT plasticized with glycerol (control) and (b) starch/PBAT plasticized with glycerol and compatibilized with citric acid

The more compact and homogeneous structures observed in Figures $2 \mathrm{~b}$ ( $1.5 \%$ citric acid), $2 \mathrm{c}(2.5 \%$ citric acid), and $3 \mathrm{~b}(3.0 \%$ citric acid) may also be responsible for the higher barrier to water vapor of these films, as commented before.

Citric acid presents a chemical structure that assumes different functions depending on its concentration in the blend. The ideal concentration is an incognita in itself because: as suggested by Reddy and Yang, ${ }^{17}$ low concentrations $(<5 \%)$ promote little improvement in resistance, as a consequence of insufficient crosslinking, while in concentrations over $5 \%$, the excess crosslinks limit the chain mobility, decreasing elongation; in excess, the residual free citric acid can act as plasticizer, improving the dispersion of polymers, but excess plasticizer (glycerol + residual citric acid) can increase the adhesiveness of the material and affect processability, as was observed in the preliminary tests and reported by other authors, ${ }^{4,10,18}$ and, the fragmentation and dissolution of the molecular structure of starch can have two effects, as mentioned above: compatibilization of polymers and/or resistance reduction.

\section{Fourier transform infrared (FT-IR) spectroscopy}

Shi et al. ${ }^{4}$ suggested that the esterification reaction in blends of corn starch, polyvinyl alcohol (PVA), glycerol, and citric acid occurs exclusively between the acid and the starch and/or PVA. However, glycerol and citric acid also allow esterification. ${ }^{19}$ Esters have two characteristic strong absorptions arising from the $\mathrm{C}=\mathrm{O}$ usually found in the range of $1800-1650 \mathrm{~cm}^{-1} \cdot{ }^{20}$ The FT-IR spectrum of the citric acid and glycerol mixtures, before and after of the heating had absorption bands in the region of $1728 \mathrm{~cm}^{-1}$ (Figure $2 \mathrm{~S}(\mathrm{c})$, supplementary 
material) and $1726 \mathrm{~cm}^{-1}$ (Figure $2 \mathrm{~S}(\mathrm{~d})$, supplementary material), respectively, related to the stretching vibration of the $\mathrm{C}=\mathrm{O}$ bond of the ester-group. These absorption peaks were not observed in the spectra of glycerol (Figure $2 \mathrm{~S}(\mathrm{a})$, supplementary material) while the spectra of the citric acid (Figure $2 \mathrm{~S}(\mathrm{~b})$, supplementary material) presented two absorption peaks related to the vibration of the $\mathrm{C}=\mathrm{O}$ bond of aliphatic carboxylic acid, at 1702 and $1747 \mathrm{~cm}^{-1}$. According to Shi et al., ${ }^{4}$ the shift of the absorption peak of carbonyl, from 1709 $\mathrm{cm}^{-1}$ in the pure citric acid to $1729 \mathrm{~cm}^{-1}$, in the blend of thermoplastic starch and citric acid, demonstrates the existence of an ester bond in this blend, confirming the esterification reaction between starch and citric acid. Reddy and Yang ${ }^{17}$ found one band at $1724 \mathrm{~cm}^{-1}$ which was ascribed to the carboxyl and ester carbonyl bands for films produced by casting with corn starch, glycerol, citric acid and sodium hypophosphite. Zhou et al. ${ }^{21}$ observed a clear new peak in the ATR-FTIR spectrum of the modified film with dodecenyl succinic anhydride located at $1726 \mathrm{~cm}^{-1}$ which was associated with $\mathrm{C}=\mathrm{O}$ ester stretch. The presence of ester carbonyl (glycerol citrate), even after the heat treatment, shows that this compound is thermally stable and that the esterification reaction is irreversible. Thus, citric acid probably reacted with glycerol during the preparation of the mixtures to obtain the films. Thus, part of the acid may not have been "available" for the formation of crosslinking with the starch. Therefore, if the action of citric acid as a cross-linking agent decreased due to the formation of ester with glycerol, one should consider the fact that the glycerol citrate compound may be, in part, responsible for the increase in the compatibility between the polymeric phases (starch/PBAT), as shown in the micrographs.

The spectrum of films with glycerol/starch/PBAT/citric acid (Figure 3S(b), supplementary material), presented one peak related to the vibration of the $\mathrm{C}=\mathrm{O}$ bond $\left(1718 \mathrm{~cm}^{-1}\right)$. This indicates esterification among the citric acid and starch and/or glycerol and/or PBAT.

The presence of carbonyl groups, cannot be used as evidence of cross-linking between starch and citric acid, because this reaction can also occur with PBAT or glycerol, and also because PBAT itself already contains ester bonds in its structure (Figure 3S(a), control supplementary material). However, when the blend is processed at high temperatures, as starch is the component in larger concentration, as compared to glycerol, esterification may occur between citric acid and starch, forming monoester bonds and/or cross links, which may result in some resistant starch granules. Furthermore, the formation of ester linkages (hydrophobic group) as previously mentioned may account for the slight reduction in WVP values of films of starch/ glycerol/PBAT/citric acid. These same ester group formed between citric acid and starch may also respond by increasing the compatibility between polymers (starch and PBAT) (Figure 3) and the low elongations value, since crosslinking by esterification reaction limited mobility of the chains.

\section{CONCLUSION}

Reactive extrusion was an efficient process for compatibilization of starch/PBAT blends using citric acid as a compatibilizing agent. The multicarboxylic structure of citric acid, along with the possible esterification reactions between starch and/or other components, may lead to the formation of crosslinks that overcome the naturally occurring bonds, making the material more resistant to water vapor and less flexible. At the same time, the acidolysis reactions are probably responsible for the decrease in film resistance with the increase in the acid concentration. In this way, the citric acid concentration must be defined according to the material application characteristics sought, with priority given either to flexibility or to resistance. In the case of films containing citric acid and polyesters, FTIR can not be used to demonstrate the occurrence of crosslinking via esterification as a consequence of the existing ester bonds in the polymer. Therefore, the effect of citric acid in starch/glycerol/PBAT/citric acid blends is clearly demonstrated by SEM.

\section{SUPPLEMENTARY MATERIAL}

The surface contour for tensile strength (MPa), elongation at

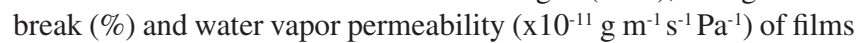
produced with cassava starch/PBAT/glycerol/citric acid, and spectrum of FT-IR of glycerol, citric acid, glycerol + citric acid without heating and glycerol + citric acid with heating; starch/glycerol/PBAT blends and starch/glycerol/PBAT/citric acid blends are show in Figures 1S, $2 \mathrm{~S}$ and $3 \mathrm{~S}$, respectively, available at http://quimicanova.sbq.org.br in pdf file, with free access.

\section{ACKNOWLEDGEMENTS}

The authors thanks CAPES for the financial support given to this work.

\section{REFERENCES}

1. Gontard, N.; Guilbert, S.; Cuq, J. L.; J. Food Sci. 1993, 58, 206

2. Gaudin, S.; Lourdin, D.; Forssell, P. M.; Colonna, P.; Carbohydr. Polym. 2000, 43, 33 .

3. Ning, W.; Jiugao, Y.; Xiaofei, M.; Ying, W.; Carbohydr. Polym. 2007, $67,446$.

4. Shi, R.; Bi, J.; Zhang, Z.; Zhu, A.; Chen, D.; Zhou, X.; Zhang, L.; Tian, W.; Carbohydr. Polym. 2008, 74, 763.

5. Ren, J.; Fu, H.; Ren, T.; Yuan, W.; Carbohydr. Polym. 2009, 77, 576.

6. Muller, R. J.; Witt, U.; Rantze, E.; Deckwer, W. D.; Polym. Degrad. Stab. 1998, 59, 203.

7. Canevarolo, S. V.; Ciência dos polímeros: um texto básico para tecnólogos e engenheiros, $2^{\mathrm{a}}$ ed., Artible: São Paulo, 2006.

8. Raquez, J-M.; Nabar, Y.; Srinivasan, M.; Shin, B-Y; Narayan, R.; Dubois, P.; Carbohydr. Polym. 2008, 74, 159.

9. Jiugao, Y.; Ning, W.; Xiaofei, M.; Starch/Staerke 2005, 57, 494

10. Shi, R.; Zhang, Z.; Liu, Q.; Han, Y.; Zhuang, L.; Chen, D.; Tian, W.; Carboydr. Polym. 2007, 69, 748.

11. Xie, F.; Yu, L.; Liu, H.; Chen, L.; Starch/Staerke 2006, 58, 131.

12. ASTM - American Society for Testing and Materials - E-96-00; Annual Book of ASTM Standards, ASTM: Philadelphia, 2000.

13. ASTM - American Society for Testing and Materials - D-882-02; Annual Book of ASTM Standards, ASTM: Philadelphia, 2002.

14. Statsoft; STATISTICA for Windows - Computer program manual, Statsoft Inc.: Tulsa, 2004.

15. Xiaofei, M.; Chang, P. R.; Jiugao, Y.; Stumborg, M.; Carbohydr. Polym. 2009, 75, 1

16. Wing. R. E.; Ind. Crops Prod. 1996, 5, 304.

17. Reddy, N.; Yang, Y.; Food Chem. 2010, 118, 702.

18. Thumwall, M.; Kuthanová, V.; Boldizar, A.; Rigdahl, M.; Carbohydr. Polym. 2008, 71, 583.

19. Holser, R. A.; J. Appl. Polym. Sci. 2008, 110, 1498.

20. Kooter, I. M.; Pierik, A. J.; Merkx, M.; Averill, B. A.; Moguilevsky, N.; Bollen, A.; Wever, R.; J. Am. Chem. Soc. 1997, 119, 11542.

21. Zhou, J.; Ren, L.; Tong, J.; Xie, L.; Liu, Z.; Carbohydr. Polym. 2009, 78, 888 . 


\section{CITRIC ACID AS MULTIFUNCTIONAL AGENT IN BLOWING FILMS OF STARCH/PBAT}

Patrícia Salomão Garcia, Maria Victória Eiras Grossmann* e Fábio Yamashita

Departamento de Ciência e Tecnologia de Alimentos, Universidade Estadual de Londrina, CP 6011, 86051-970 Londrina - PR, Brasil Suzana Mali

Departamento de Bioquímica, Universidade Estadual de Londrina, CP 6011, 86051-970 Londrina - PR, Brasil

Luiz Henrique Dall'Antonia e Wagner José Barreto

Departamento de Química, Universidade Estadual de Londrina, CP 6011, 86051-970 Londrina - PR, Brasil

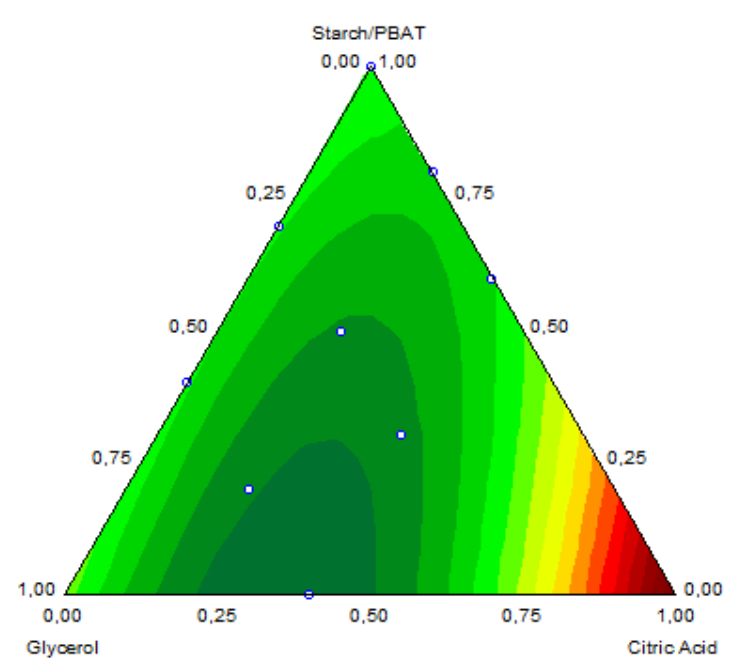

(a)

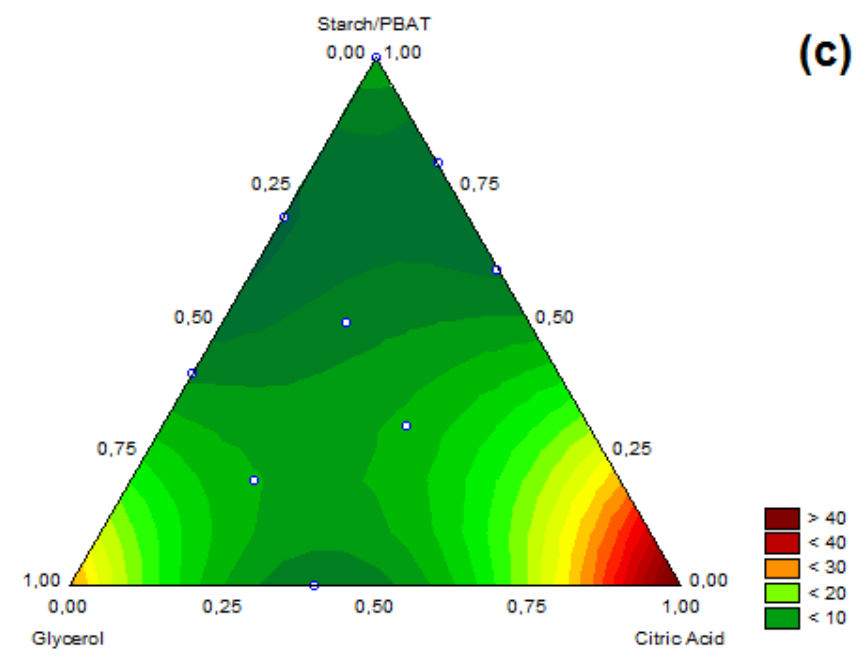

Figure 1S. Surface contour for (a) tensile strength (MPa), (b) elongation at break (\%) and (c) water vapor permeability $\left(x 10^{-11} \mathrm{~g} \mathrm{~m}^{-1} \mathrm{~s}^{-1} \mathrm{~Pa}^{-1}\right)$ of films produced with cassava starch/PBAT/glycerol/citric acid

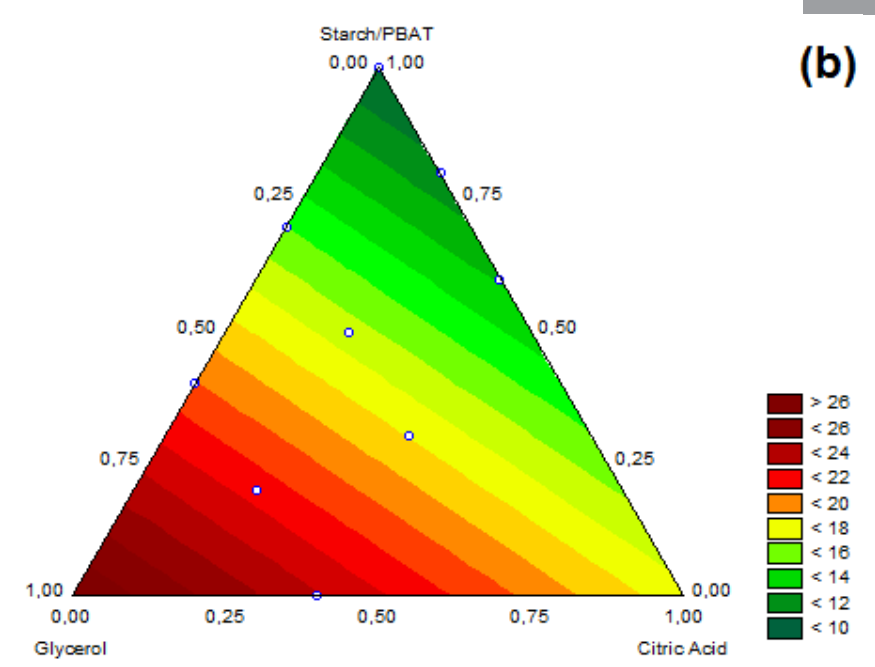

(c)

*e-mail: victoria@uel.br 


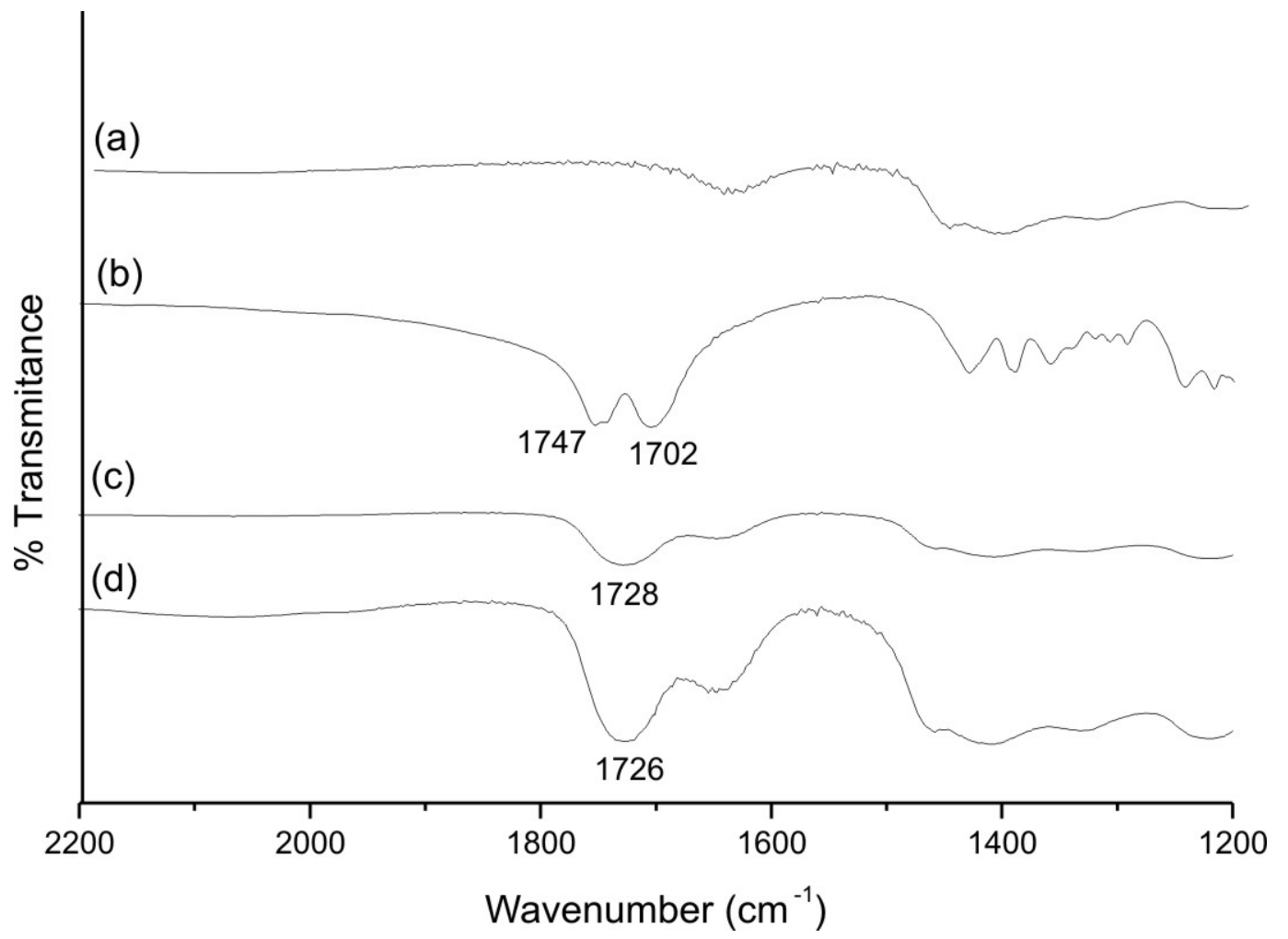

Figure 2S. Spectrum of FT-IR of: (a) glycerol, (b) citric acid, (c) glycerol + citric acid without heating and (d) glycerol + citric acid with heating

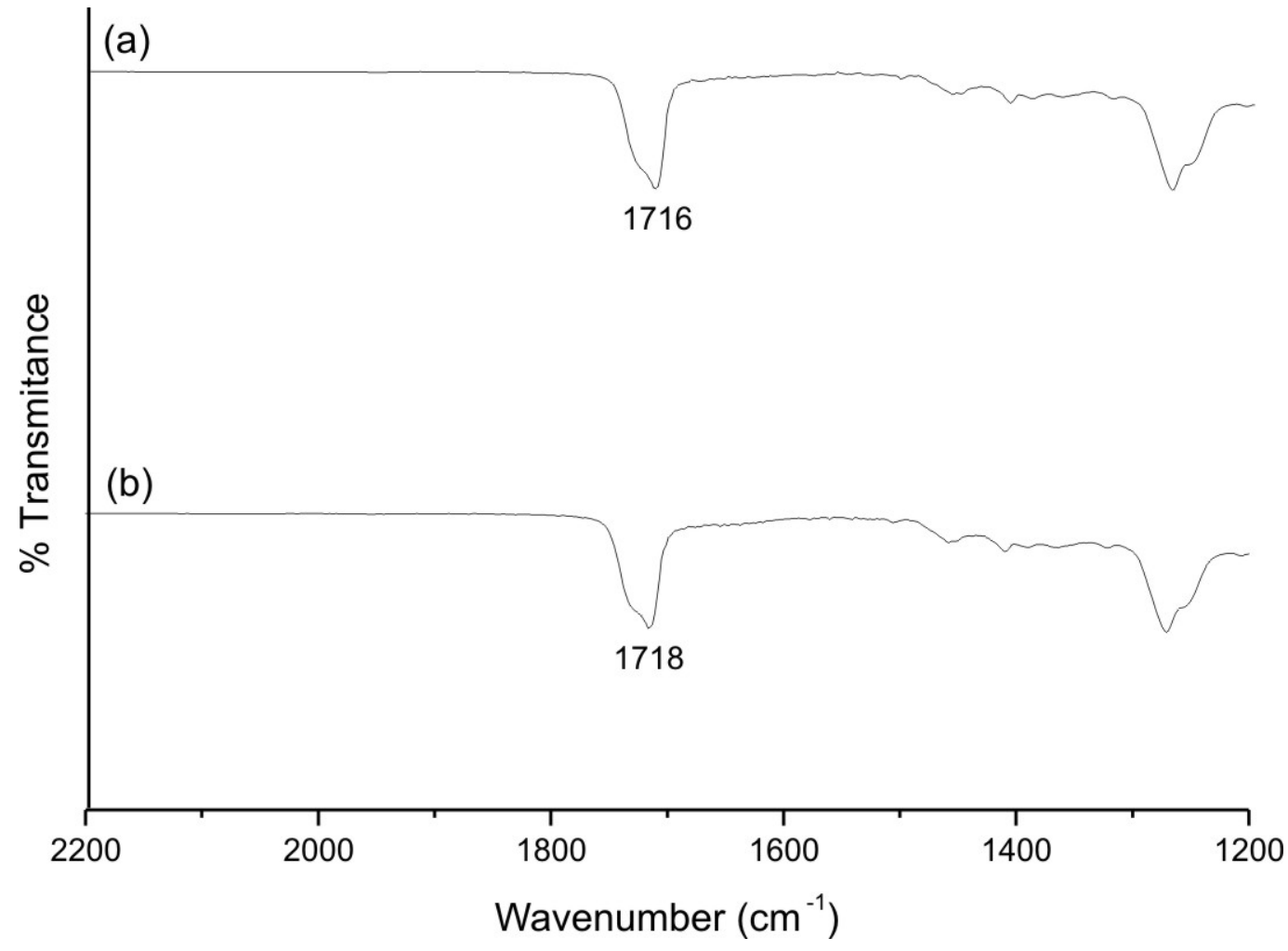

Figure 3S. Spectrum of FT-IR of: (a) starch/glycerol/PBAT and (b) starch/glycerol/ PBAT/citric acid 